\title{
Properties of Zinc Ferrite Nanoparticles Due to PVP Mediation and Annealing at $500^{\circ} \mathrm{C}$
}

\author{
Doris 0. Okoroh ${ }^{1,2 *}$, Jude 0. Ozuomba1, Samson 0. Aisida ${ }^{3}$, Paul U. Asogwa ${ }^{3}$ \\ ${ }^{1}$ Department of Physics, Imo State University, Owerri, Nigeria \\ ${ }^{2}$ Department of Physics, Federal College of Education (Technical), Omoku, Nigeria \\ ${ }^{3}$ Department of Physics and Astronomy, University of Nigeria, Nsukka, Nigeria \\ Email: *dorisokoroh@gmail.com
}

How to cite this paper: Okoroh, D.O., Ozuomba, J.O., Aisida, S.O. and Asogwa, P.U. (2019) Properties of Zinc Ferrite Nanoparticles Due to PVP Mediation and Annealing at $500^{\circ} \mathrm{C}$. Advances in Nanoparticles, 8, 36-45.

https://doi.org/10.4236/anp.2019.82003

Received: April 28, 2019

Accepted: May 24, 2019

Published: May 27, 2019

Copyright $\odot 2019$ by author(s) and Scientific Research Publishing Inc. This work is licensed under the Creative Commons Attribution International License (CC BY 4.0).

http://creativecommons.org/licenses/by/4.0/

\begin{abstract}
In contributing to the improvement of Ferrite Magnetic nanoparticles, the effects of Poly (Vinyl Pyrrolidone) (PVP) and annealing on the structural and magnetic properties of Zinc ferrite nanoparticles (ZFNPs) synthesis were investigated in this work. The effects were evaluated using the X-ray diffraction (XRD) spectroscopy, Scanning electron microscopy (SEM), Fourier transform infrared spectroscopy (FTIR) and Vibrating sample magnetometer (VSM). The XRD analysis confirms a good formation of the inverse spinel crystal structure with an average particle size of $1.3 \mathrm{~nm}$ to $15.2 \mathrm{~nm}$ and from $1.6 \mathrm{~nm}$ to $21.1 \mathrm{~nm}$ for the ZFNPs as-prepared and PVP mediated ZFNPs for the un-annealed and annealed samples, respectively. The SEM image reveals an increase in the particle size for both the as-prepared and PVP mediated samples after annealing at $500^{\circ} \mathrm{C}$. The FTIR also reveals the inverse spinel structure for the as-prepared and annealed samples, which witnesses a vibrational red shift towards a higher wave number for the annealed samples. The VSM analysis indicates the superparamagnetic behavior of PVP mediated and annealed sample with zero remanence magnetization $(\mathrm{Mr})$ and Coercivity (Hc). The saturation magnetization $(\mathrm{Ms})$ increases from $1.31 \mathrm{emu} / \mathrm{g}$, for the as-prepared samples, to $4.31 \mathrm{emu} / \mathrm{g}$ after the annealing and from $1.18 \mathrm{emu} / \mathrm{g}$, for the PVP mediated, to $6.38 \mathrm{emu} / \mathrm{g}$ after annealing. These effects have been attributed to the cationic re-arrangement on the lattice site after the annealing. This presents a superior material for various applications in nanotechnology.
\end{abstract}

\section{Keywords}

ZFNPs, Poly (Vinyl Pyrrolidone), Annealing, Super Paramagnetic, Properties

\section{Introduction}

The advancement of Nanoparticles (NP) in recent times has been superior, espe- 
cially due to the enhancement of their properties in relation to their bulk materials [1] [2]. The Ferrite Magnetic nanoparticles (FMNP) are grouped as the spinel, the hexagonal and the garnet, respectively, based on their crystal structure. Their distinct special crystal structure and magnetic properties are applied in various biomedicine, industries and material science such as the encapsulation of drug for drug delivery to a targeted site to circumvent side effect problems [3] [4], cancerous cell/tumor treatment via magnetic resonance imaging (MRI), information storage in modern technology [5], and therapeutics via hyperthermia [2] [6]. This is achieved using various synthetic methods such as hydrothermal [2] [7], sol-gel [8], microemulsion [9], thermal decomposition [10] [11], and chemical co-precipitation [12]. Their adopted procedures in the synthesis methods have a significant influence on the morphology, size and the shape of the NP [13]. Co-precipitation method has been shown to be the most appropriate for biomedical application since it does not require any complex reactants or toxic materials and is often conducted under room temperature [14].

However, the most commonly studied FMNP is the spinel ferrite (SF) nanocrystals. These are very important inorganic nanomaterials when compared to their bulk counterpart as well as their optical, electronic, electrical and magnetic properties, respectively [14] [15] [16] [17]. The cubic structured SFs belong to the class of oxides with exceptional magnetic properties that have no preferred directions of magnetization [18] [19]. They have the crystal structure of the natural spinel of $\mathrm{AB}_{2} \mathrm{O}_{4}$ in which $\mathrm{A}(\mathrm{Zn}, \mathrm{Mn}, \mathrm{Co}$, or $\mathrm{Ni})$ and $\mathrm{B}(\mathrm{Fe})$ display tetrahedral and octahedral cation sites respectively, whereas, $\mathrm{O}$ indicates the oxygen anion site [3] [17] [20]. They occur as magnetic semiconductors capable of generating magnetic nanospheres as a result of their simplicity and are non-toxicity in preparation [21]. The Zinc ferrite nanoparticles (ZFNPs) are SF nanoparticle.

There are challenges in controlling the shapes and dispersibility of the ZFNPs due to their large surface to volume ratio, which induces the large surface energy that is thermodynamically unstable and then produces an aggregation [22]. The application of this NP is limited, sequel to the large size. However, it has been shown that to increase the saturation magnetization in the super-paramagnetic region of materials is a superior method to advance their improvement [23]. To enhance the optimal applications of the NPs, polymer encapsulation is needed to reduce the agglomeration effect [14] [24]. ZFNPs encapsulated with polymers enhanced their stability, biocompatibility, conjugating ability and as well reduce the agglomeration for various applications. The hydrophilicity, non-toxicity, dispersibility, and biocompatibility properties of Poly (Vinyl Pyrrolidone) (PVP) make it an excellent capping agent of ZFNPs [14].

In one of such studies, [9] has shown that it is possible to prepare designed oxide nanoparticles using stable colloidal solution as an aqueous pseudophase. In their work, [25] showed in the nonstoichiometry of ZFNPS as a function of the particle size that, with a decrease in the particle size, the compositional range of the zinc-ferrite spinel broadened. Also, [26] in their study showed that in the 
absence of PVP, the ZFNPS exhibited a paramagnetic behavior, whereas in the presence of PVP, they have super-paramagnetic behavior. However, these ZFNPS has shown to have improved colloidal aqueous stability as well as adequate antibacterial activities [7] [27].

In this work, we report on the surface effect of PVP mediated and the annealing on the structural and magnetic properties of ZFNPs using the co-precipitation method. The objectives include evaluating the effect of the PVP and the annealing on the particle size, determining the degree of crystallinity and the phase composition, and establishing the presence of the metal oxide bands. The results should present a superior material for the various applications.

\section{Materials and Method}

The analytical grade, without further purification, of iron (III) nitrate nonahydrates $\left(\mathrm{Fe}\left(\mathrm{NO}_{3}\right)_{3} \cdot 9 \mathrm{H}_{2} \mathrm{O}\right) 99 \%$, zinc nitrate hexahydrate $\left(\mathrm{Zn}\left(\mathrm{NO}_{3}\right)_{2} \cdot 6 \mathrm{H}_{2} \mathrm{O}\right) 99 \%$, poly (vinyl pyrrolidone) $(\mathrm{C} 6 \mathrm{H} 9 \mathrm{NO}) \mathrm{n} 99.9 \%(\mathrm{MW}=29,000)$ were used as precursors in the experiment. These were purchased from Sigma Aldrich and used without further purification. Distilled water (DW) was used all through the synthesis procedures.

\subsection{Preparation of Zinc Ferrite Nanoparticle-Mediated with PVP}

An aqueous solution of $0.2 \mathrm{~mm}$ of iron nitrate in $100 \mathrm{ml}$ of DW and $0.1 \mathrm{~mm}$ of Zinc nitrate in $50 \mathrm{ml}$ of DW were prepared. The mixed reaction was obtained in the stoichiometric ratio $(\mathrm{Fe}: \mathrm{Zn}=2: 1)$ and stirred with a magnetic stirrer for 2 hours to obtain a homogeneous solution. The obtained solution was added, in a dropwise, into a reaction container of $100 \mathrm{ml}$ of DW at $90^{\circ} \mathrm{C}$ of $0.1 \mathrm{~g}$ PVP. The mixture was poured into an evaporating dish and heat at $80^{\circ} \mathrm{C}$ in an evaporating heater to evaporate the water and later transferred to the oven for $24 \mathrm{hrs}$ to complete the drying. The dried orange colored solid ZFNPs, and the PVP mediated ZFNPs that remained, were pulverized to form a powder. The ZFNPs powder and the polymer mediated ZFNPs were washed several times and later annealed at $500^{\circ} \mathrm{C}$ for $3 \mathrm{hrs}$ to enhance the crystallinity of the nanocrystals and the decomposition of organic compounds in an air atmosphere.

$$
\mathrm{Zn}^{2+}+\mathrm{Fe}^{2+}+\mathrm{H}^{+} \rightarrow \mathrm{ZnFe}_{2} \mathrm{O}_{4}+\mathrm{H}_{2} \mathrm{O}
$$

\subsection{Characterization}

The PVP mediated ZFNPS samples were characterized by powder X-ray diffraction (XRD). The powder crystallite samples were used at room temperature, employing a Shimadzu diffractometer model XRD 6000 with the $\mathrm{CuK}_{\alpha}(0.154 \mathrm{~nm})$ radiation source in a $2 \theta$ range of $10^{\circ}-80^{\circ}$. The surface morphology and the elemental composition of the samples were determined by the Scanning Electron Microscope (SEM) obtained using JEOL_SEM1010 SEM instrument. The elemental compositions of the samples were obtained by the energy-dispersive X-ray spectroscopy (EDX) attached to SEM microscope. The Fourier Transform 
Infrared (FTIR) (PerkinElmer FT-IR spectra 1650, version 10.03.02) model spectrometer with 256 scans and $6 \mathrm{~cm}^{-1}$ resolution in the range of $4000 \mathrm{~cm}^{-1}$ to $500 \mathrm{~cm}^{-1}$ gave the functional groups. The magnetization via hysteresis loop at room temperature was conducted using a vibrating sample magnetometer (VSM) (lake shore 4700) with a magnetic field range from -5 KOe to +5 KOe. Noteworthy is that the microstructure and morphology of the nanoparticles is not within the scope of this study hence the samples were not exposed to the transmission electron miscroscopy.

\section{Results and Discussions}

\subsection{SEM and EDX Analysis}

The SEM images in Figures 1(a)-(d) shows the size distribution of the ZFNPs as-prepared, the PVP mediated samples and the annealed samples at $500^{\circ} \mathrm{C}$. The ZFNPs as-prepared is highly agglomerated with an average particle size of 52 $\mathrm{nm}$, which decreases to $41 \mathrm{~nm}$ after the annealing. The effect of the PVP on the ZFNP is in reducing the agglomeration to an average particle size of $51 \mathrm{~nm}$, whereas, after the annealing the particle reduces to $30 \mathrm{~nm}$. It is obvious that the samples obtained at $500^{\circ} \mathrm{C}$ were uniform in their morphology and decreased in particle size. The decrease in size is as a result of the melting of their surfaces, which were also observed in nickel ferrite and cobalt ferrite [6]. The EDX analysis shows strong signal in the iron and zinc region, which emphasized the presence of iron and zinc nanoparticles with optical absorption peak $\approx 6.4 \mathrm{keV}$ and $\approx$ $1.0 \mathrm{keV}$, respectively, sequel to the Surface Plasmon Resonance (SPR). Along with iron and zinc in the EDX graph are oxygen and carbon, which might be caused by content present in the polymer. The percentage of the Fe and Zn content increases, respectively, after the annealing.

\subsection{XRD Analysis}

In the $\mathrm{XRD}$ result is shown the formation of cubic spinel structures without the noticeable traces of impurity phases for the PVP mediated samples coupled with annealing (Figure 2). The backgrounds of the un-annealed samples (Figure 2(a) and Figure 2(c)) are seen to be different. The index peaks at (220), (311), (400), (422), (511), (440) and (533), respectively, reveals the cubic spinel of Zinc ferrite without the impurity phase (JCPDS card no. 36-0398). Further analysis on the XRD outputs was carried out using the Scherer formula, given by the equation,

$$
D=\frac{0.9 \lambda}{\beta \cos \cos \theta}
$$

where $D$ is the crystalline size $(\mathrm{nm}), \lambda$ is the $\mathrm{X}$-ray wavelength $(\lambda=1.5406 \AA$ ), $\beta$ is the full width at half maximum (FWHM) intensity measured in radians and $\theta$ is the Bragg diffraction angle [28]. The strain has been considered during the calculation of the crystallite size [29]. The analysis result confirms the average particle size of $1.3 \mathrm{~nm}$ to $15.2 \mathrm{~nm}$ and from $1.6 \mathrm{~nm}$ to $21.1 \mathrm{~nm}$ in the ZFNPs as-prepared to the annealed samples, as well as in the PVP mediated sample (Table 1). 

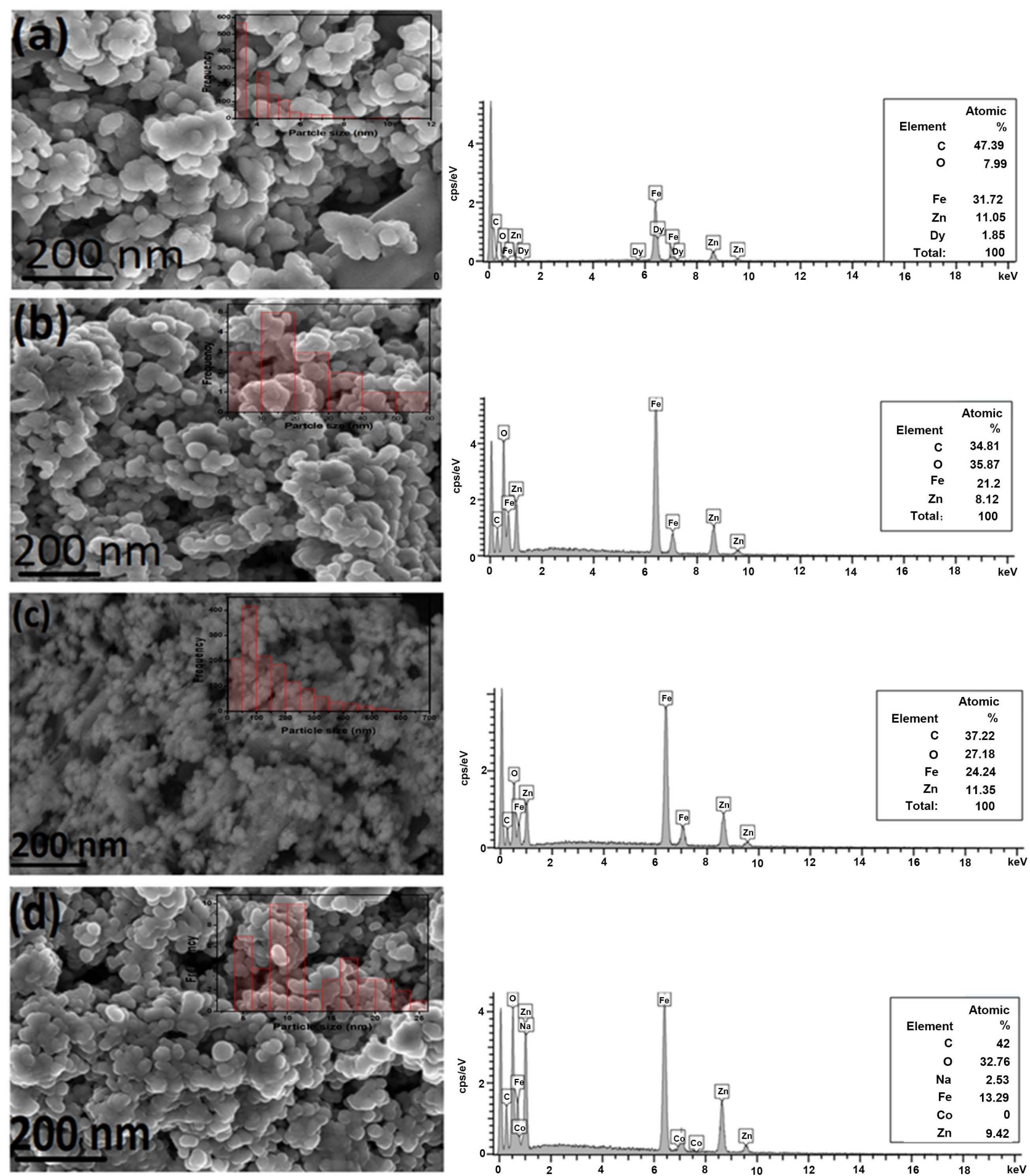

Figure 1. The SEM micrograph (left panels) and the EDX analysis (right panels) of (a) ZFNPs as-prepared (un-annealed), (b) ZFNPs as-prepared (annealed), (c) ZFNPs PVP mediated (un-annealed), and (d) ZFNPs PVP mediated (annealed).

\subsection{FTIR Analysis}

The FTIR analysis results of the ZFNPs as-prepared, the PVP mediated samples and the annealed samples are presented in Figure 3. The peaks at $750 \mathrm{~cm}^{-1}$ and $704 \mathrm{~cm}^{-1}$ are due to the stretching vibration mode for Fe-O and $\mathrm{Zn}-\mathrm{O}$, respectively. 


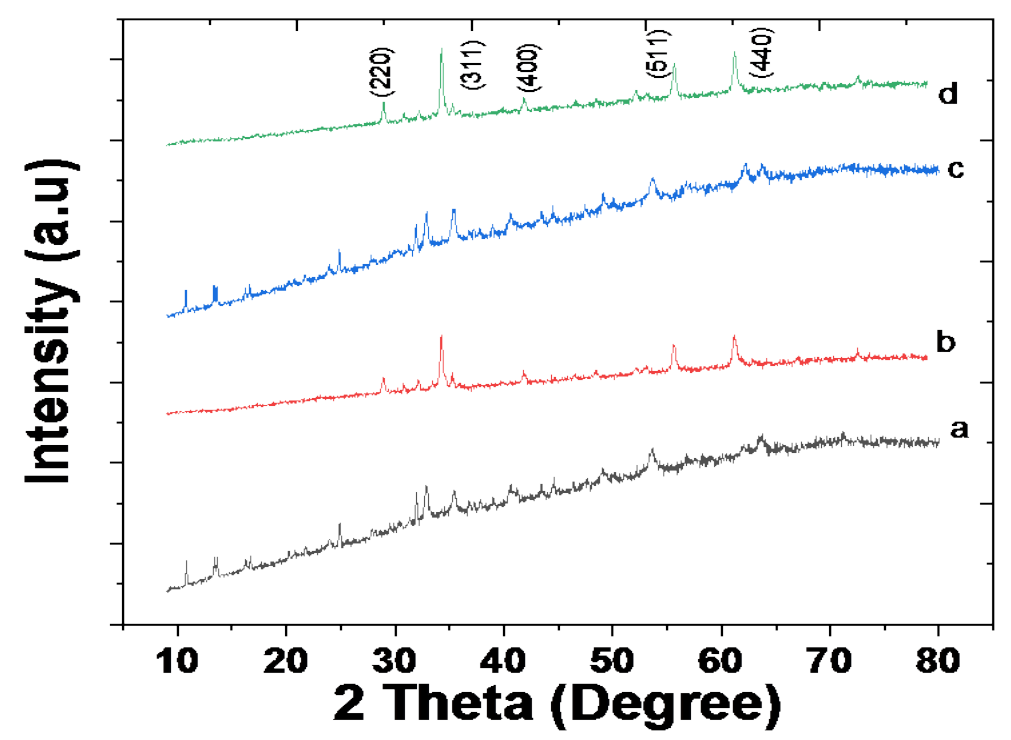

Figure 2. The XRD analysis of the (a) ZFNPs as-prepared (gray line), (b) ZFNPs as-prepared and annealed at $500^{\circ} \mathrm{C}$ (red line), (c) PVP mediated ZFNPs (blue line), and (d) PVP mediated ZFNPs and annealed at $500^{\circ} \mathrm{C}$ (green line).

Table 1. Crystalline sizes of the ZFNPs as-prepared, the PVP mediated and the calcined samples, respectively.

\begin{tabular}{|c|c|c|c|c|c|c|}
\hline \multirow{2}{*}{ Samples } & \multirow{2}{*}{ Dopant } & \multirow{2}{*}{$\mathrm{T}_{\mathrm{c}}\left({ }^{\circ} \mathrm{C}\right)$} & \multirow{2}{*}{$2 \theta$} & \multirow{2}{*}{ FWHM } & \multicolumn{2}{|c|}{ Average particles size $(\mathrm{nm})$} \\
\hline & & & & & $\mathrm{r}^{*}$ & $\mathrm{r}^{* *}$ \\
\hline ZFNPs & - & - & 32.8399 & 6.43522 & 1.300 & - \\
\hline ZFNPs & - & 500 & 35.2463 & 0.56863 & - & 15.200 \\
\hline ZFNPs & PVP & - & 36.2015 & 5.32252 & 1.600 & - \\
\hline ZFNPs & PVP & 500 & 35.2806 & 0.41042 & - & 21.100 \\
\hline
\end{tabular}

$\mathrm{r}^{*}$ before annealing; $\mathrm{r}^{* *}$ after annealing.

The peaks at $1055 \mathrm{~cm}^{-1}$ in the ZFNPs as-prepared and $1066 \mathrm{~cm}^{-1}$ in the PVP mediated ZFNPs are attributed to the C-C stretching that changes to $1030 \mathrm{~cm}^{-1}$ after the annealing, respectively. The Carbonyl group $(\mathrm{C}=\mathrm{O})$ absorbs energy at $1634 \mathrm{~cm}^{-1}$ in the ZFNPs as-prepared and at $1622 \mathrm{~cm}^{-1}$ in the PVP mediated samples, which increased to $1634 \mathrm{~cm}^{-1}$ and $17131 \mathrm{~cm}^{-1}$ after the annealing. The peaks at $1429 \mathrm{~cm}^{-1}$ in the ZFNPs as-prepared and at $1330 \mathrm{~cm}^{-1}$ in the PVP mediated ZFNPs are attributed to $\mathrm{CH}_{2}$ bending, which increases to $1490 \mathrm{~cm}^{-1}$ and $1525 \mathrm{~cm}^{-1}$ after the annealing. The broadest peaks observed at $3204 \mathrm{~cm}^{-1}$ in the ZFNPs as-prepared and at $3216 \mathrm{~cm}^{-1}$ in the PVP mediated ZFNPs are due to an $\mathrm{O}-\mathrm{H}$ group, which gives no peak for ZFNPs as-prepared and is $2975 \mathrm{~cm}^{-1}$ in the PVP mediated ZFNPs. The presence of the functional groups; $\mathrm{C}=\mathrm{O}, \mathrm{C}-\mathrm{N}, \mathrm{C}-\mathrm{C}$, $\mathrm{C}-\mathrm{H}$ and $\mathrm{O}-\mathrm{H}$, confirms the presence of the PVP compound in ZFNPs.

\subsection{VSM Analysis}

Figure 4 shows the relationship between the magnetic field and the magnetization of the sample as-prepared, and at $500^{\circ} \mathrm{C}$. The result indicates that the samples 


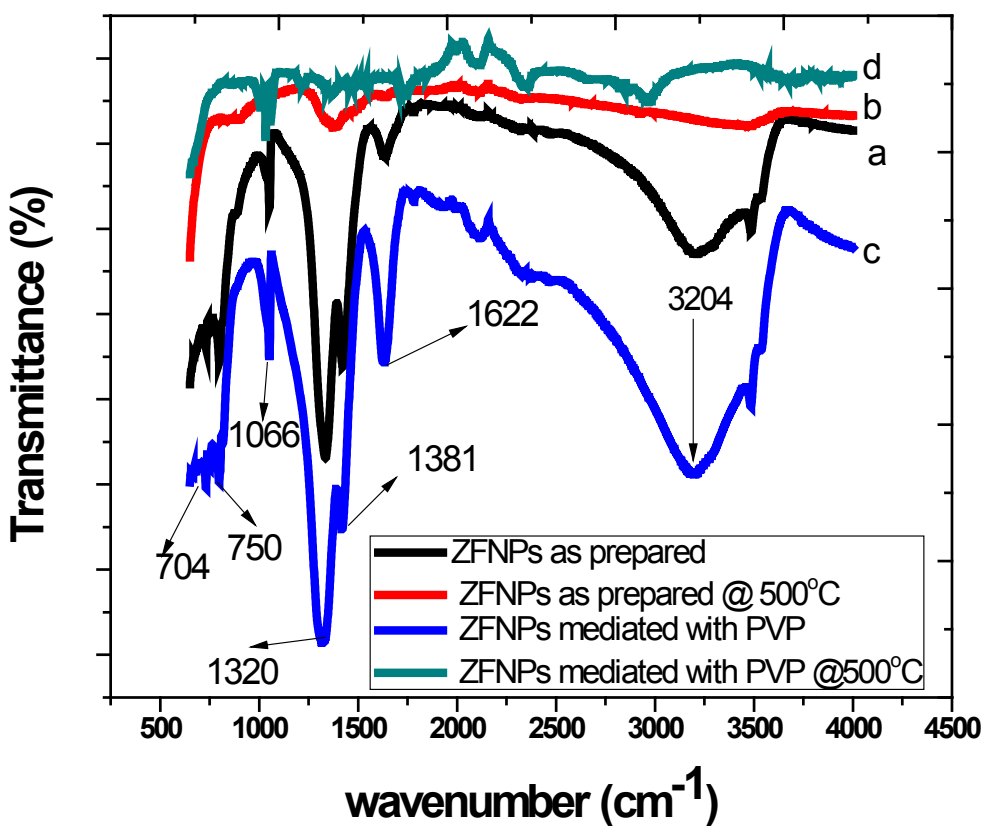

Figure 3. The FTIR analysis of the (a) ZFNPs as prepared (black line), (b) ZFNPs annealed at $500^{\circ} \mathrm{C}$ (red line), (c) ZFNPs mediated with PVP (blue line), (d) ZFNPs mediated with PVP and annealed at $500^{\circ} \mathrm{C}$ (green line).

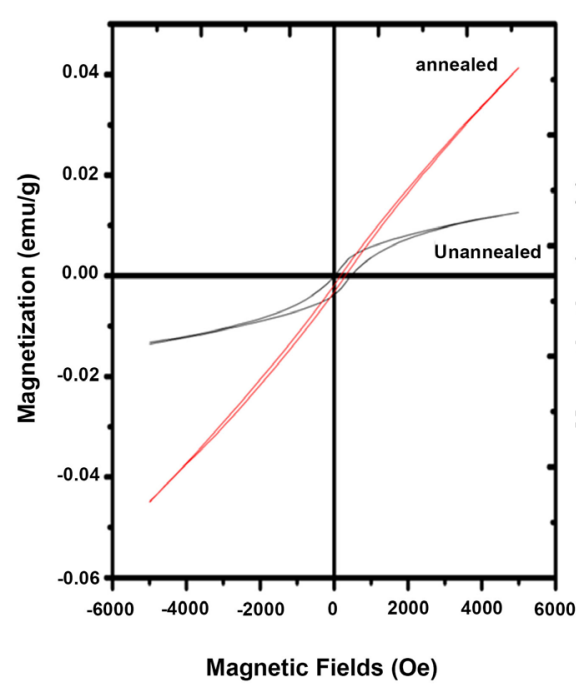

(a)

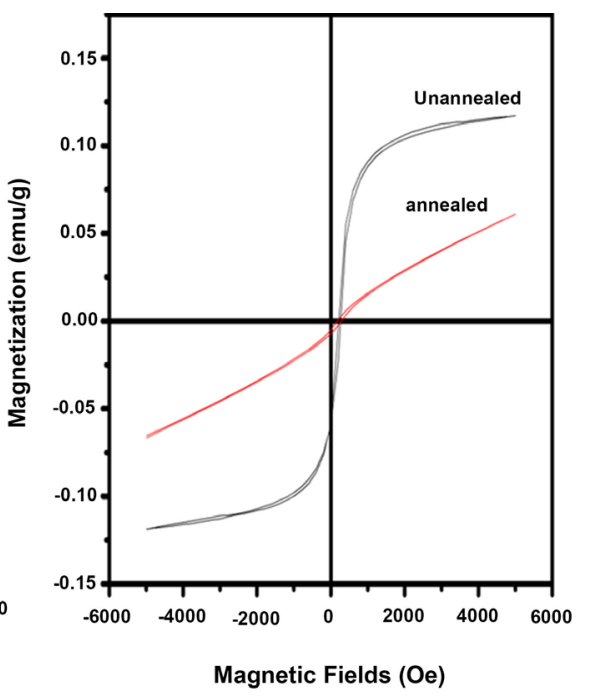

(b)

Figure 4. The VSM analysis of the un-annealed and the annealed (a) ZFNPs as-prepared (left), and (b) PVP mediated ZFNPs (right).

showed zero coercivity and zero remanent magnetization (no hysteresis) at the $500^{\circ} \mathrm{C}$ annealed temperature when compared with the un-annealed sample. This suggests that the superparamagnetic (SPM) behavior is in consonance with the state-of-the-art results of [30]. The hysteresis loop of the samples confirms that the magnetic behavior of the ZFNPs is highly influenced by the mediating PVP and the annealing, moving it from the ferromagnetic (un-annealed) to the SPM behavior (annealed). 


\section{Conclusion}

The ZFNPs as-prepared, the PVP mediated and the annealed were synthesized via the co-precipitation method. The effects of the PVP and the annealing at $500^{\circ} \mathrm{C}$ on the structural and magnetic properties, respectively, have been analyzed. The XRD analysis reveals the increase in the crystallite size after the PVP mediation and the annealing of the samples, respectively. The XRD analysis of the annealed samples indicates the intense and sharp peaks when compared to the un-annealed samples. The SEM images reveal increment in the particle size of the PVP mediated and the annealed samples, respectively. The EDX analysis has revealed the strong signals of the component elements in the samples. The FTIR analysis has confirmed the presence of the PVP on the surface of ZFNPs with a red shift of the annealed sample as a result of the cationic distribution on the lattice sites. The magnetic properties of the samples changed from a ferromagnetic to an SPM as an effect of the PVP mediated and the annealing. This SPM behavior of the ZFNPs as-prepared and the PVP mediated, respectively, has been achieved by annealing the samples at $500^{\circ} \mathrm{C}$ for $3 \mathrm{hrs}$. The PVP mediated and annealing effects on the structural and magnetic properties of ZFNPs present a superior material for sundry applications. However, further studies on the morphology and the microstructure of ZFNPs are imperative in enhancing the applicability.

\section{Conflicts of Interest}

The authors declare no conflicts of interest regarding the publication of this paper.

\section{References}

[1] Naidu, K.C.B. and Madhuri, W. (2017) Microwave Processed Bulk and Nano NiMg Ferrites: A Comparative Study on X-Band Electromagnetic Interference Shielding Properties. Materials Chemistry and Physics, 187, 164-176. https://doi.org/10.1016/j.matchemphys.2016.11.062

[2] Samavati, A. and Ismail, A.F. (2017) Antibacterial Properties of Copper-Substituted Cobalt Ferrite Nanoparticles Synthesized by Co-Precipitation Method. Particuolo$g y, 30,158-163$. https://doi.org/10.1016/j.partic.2016.06.003

[3] Sharma, R., Thakur, P., Kumar, M., Thakur, N., Negi, N.S., Sharma, P. and Sharma, V. (2016) Improvement in Magnetic Behaviour of Cobalt Doped Magnesium Zinc Nano-Ferrites via Co-Precipitation Route. Journal of Alloys and Compounds, 684, 569-581. https://doi.org/10.1016/j.jallcom.2016.05.200

[4] Tartaj, P., del Puerto Morales, M., Veintemillas-Verdaguer, S., González-Carreño, T. and Serna, C.J. (2003) The Preparation of Magnetic Nanoparticles for Applications in Biomedicine. Journal of Physics D: Applied Physics, 36, R182. https://doi.org/10.1088/0022-3727/36/13/202

[5] Dantas, J., Leal, E., Mapossa, A.B., Cornejo, D.R. and Costa, A.C.F.M. (2017) Magnetic Nanocatalysts of $\mathrm{Ni}_{0.5} \mathrm{Zn}_{0.5} \mathrm{Fe}_{2} \mathrm{O}_{4}$ Doped with $\mathrm{Cu}$ and Performance Evaluation in Transesterification Reaction for Biodiesel Production. Fuel, 191, 463-471. https://doi.org/10.1016/j.fuel.2016.11.107 
[6] Naseri, M.G., Saion, E.B., Hashim, M., Shaari, A.H. and Ahangar, H.A. (2011) Synthesis and Characterization of Zinc Ferrite Nanoparticles by a Thermal Treatment Method. Solid State Communications, 151, 1031-1035. https://doi.org/10.1016/j.ssc.2011.04.018

[7] Yeary, L.W., Moon, J.W., Rawn, C.J., Love, L.J., Rondinone, A.J., Thompson, J.R., Chakoumakos, B.C. and Phelps, T.J. (2011) Magnetic Properties of Bio-Synthesized Zinc Ferrite Nanoparticles. Journal of Magnetism and Magnetic Materials, 323, 3043-3048. https://doi.org/10.1016/j.jmmm.2011.06.049

[8] Zaharieva, K., Rives, V., Tsvetkov, M., Cherkezova-Zheleva, Z., Kunev, B., Trujillano, R., Mitov, I. and Milanova, M. (2015) Preparation, Characterization and Application of Nanosized Copper Ferrite Photocatalysts for Dye Degradation under UV Irradiation. Materials Chemistry and Physics, 160, 271-278.

https://doi.org/10.1016/j.matchemphys.2015.04.036

[9] Grasset, F., Labhsetwar, N., Li, D., Park, D.C., Saito, N., Haneda, H., Cador, O., Roisnel, T., Mornet, S., Duguet, E., Etourneau, J. and Portier, J. (2002) Synthesis and Magnetic Characterization of Zinc Ferrite Nanoparticles with Different Environments: Powder, Colloidal Solution, and Zinc Ferrite-Silica Core-Shell Nanoparticles. Langmuir, 18, 8209-8216.

[10] Naseri, M.G., Halimah, M.K., Dehzangi, A., Kamalianfar, A., Saion, E.B. and Majlis, B.Y. (2014) A Comprehensive Overview on the Structure and Comparison of Magnetic Properties of Nanocrystalline Synthesized by a Thermal Treatment Method. Journal of Physics and Chemistry of Solids, 75, 315-327. https://doi.org/10.1016/j.jpcs.2013.11.004

[11] Wu, W., He, Q. and Jiang, C. (2008) Magnetic Iron Oxide Nanoparticles: Synthesis and Surface Functionalization Strategies. Nanoscale Research Letters, 3, 397. https://doi.org/10.1007/s11671-008-9174-9

[12] Laurent, S., Forge, D., Port, M., Roch, A., Robic, C., Vander Elst, L. and Muller, R.N. (2008) Magnetic Iron Oxide Nanoparticles: Synthesis, Stabilization, Vectorization, Physicochemical Characterizations, and Biological Applications. Chemical Reviews, 108, 2064-2110. https://doi.org/10.1021/cr068445e

[13] Berry, C.C. and Curtis, A.S. (2003) Functionalisation of Magnetic Nanoparticles for Applications in Biomedicine. Journal of physics D: Applied physics, 36, R198. https://doi.org/10.1088/0022-3727/36/13/203

[14] Afzal, S., Khan, R., Zeb, T., ur Rahman, M., Ali, S., Khan, G., ur Rahman, Z., Hussain, A., et al. (2018) Structural, Optical, Dielectric and Magnetic Properties of PVP Coated Magnetite $\left(\mathrm{Fe}_{3} \mathrm{O}_{4}\right)$ Nanoparticles. Journal of Materials Science: Materials in Electronics, 29, 20040-20050. https://doi.org/10.1007/s10854-018-0134-6

[15] Kombaiah, K., Vijaya, J.J., Kennedy, L.J., Bououdina, M., Kaviyarasu, K., Ramalingam, R.J., Munusamy, M.A. and AlArfaj, A. (2017) Effect of $\mathrm{Cd}^{2+}$ Concentration on $\mathrm{ZnFe}_{2} \mathrm{O}_{4}$ Nanoparticles on the Structural, Optical and Magnetic Properties. Optik, 135, 190-199. https://doi.org/10.1016/j.ijleo.2017.01.066

[16] Hcini, S., Selmi, A., Rahmouni, H., Omri, A. and Bouazizi, M.L. (2017) Structural, Dielectric and Complex Impedance Properties of $\mathrm{T}_{0.6} \mathrm{Co}_{0.4} \mathrm{Fe}_{2} \mathrm{O}_{4}(\mathrm{~T}=\mathrm{Ni}, \mathrm{Mg})$ Ferrite Nanoparticles Prepared by Sol Gel Method. Ceramics International, 43, 2529-2536. https://doi.org/10.1016/j.ceramint.2016.11.055

[17] Satalkar, M., Kane, S.N., Kumaresavanji, M. and Araujo, J.P. (2017) On the Role of Cationic Distribution in Determining Magnetic Properties of $\mathrm{Zn}_{0.7-\mathrm{x}} \mathrm{NixMg}_{0.2} \mathrm{Cu}_{0.1} \mathrm{Fe}_{2} \mathrm{O}_{4}$ Nano Ferrite. Materials Research Bulletin, 91, 14-21. https://doi.org/10.1016/j.materresbull.2017.03.021 
[18] Smit, J. (1971) Magnetic Properties of Materials. McGraw-Hill, New York.

[19] Snelling, E.C. (1988) Soft Ferrites, Properties and Applications. Butter Worth and Co. Ltd., London.

[20] Petrova, E., Kotsikau, D. and Pankov, V. (2015) Structural Characterization and Magnetic Properties of Sol-Gel Derived $\mathrm{Zn}_{\mathrm{x}} \mathrm{Fe}_{3-\mathrm{x}} \mathrm{O}_{4}$ Nanoparticles. Journal of Magnetism and Magnetic Materials, 378, 429-435. https://doi.org/10.1016/j.jmmm.2014.11.076

[21] Sharma, R., Thakur, P., Sharma, P. and Sharma, V. (2017) Ferrimagnetic $\mathrm{Ni}^{2+}$ Doped $M g-Z n$ Spinel Ferrite Nanoparticles for High Density Information Storage. Journal of Alloys and Compounds, 704, 7-17. https://doi.org/10.1016/j.jallcom.2017.02.021

[22] Abbas, M., Rao, B.P. and Kim, C. (2014) Shape and Size-Controlled Synthesis of Ni Zn Ferrite Nanoparticles by Two Different Routes. Materials Chemistry and Physics, 147, 443-451. https://doi.org/10.1016/j.matchemphys.2014.05.013

[23] Karimi, Z., Karimi, L. and Shokrollahi, H. (2013) Nano-Magnetic Particles Used in Biomedicine: Core and Coating Materials. Materials Science and Engineering. $C$, 33, 2465-2475. https://doi.org/10.1016/j.msec.2013.01.045

[24] Hankare, P.P., Sankpal, U.B., Patil, R.P., Jadhav, A.V., Garadkar, K.M. and Chougule, B.K. (2011) Magnetic and Dielectric Studies of Nanocrystalline Zinc Substituted $\mathrm{Cu}-\mathrm{Mn}$ Ferrites. Journal of Magnetism and Magnetic Materials, 323, 389-393. https://doi.org/10.1016/j.jmmm.2010.08.050

[25] Makovec, D. and Drofenik, M. (2008) Non-Stoichiometric Zinc-Ferrite Spinel Nanoparticles. Journal of Nanoparticle Research, 10, 131-141. https://doi.org/10.1007/s11051-008-9400-5

[26] Kamari, H., Naseri, M. and Saion, E. (2014) A Novel Research on Behavior of Zinc Ferrite Nanoparticles in Different Concentration of Poly (vinyl pyrrolidone) (PVP). Metals, 4, 118-129. https://doi.org/10.3390/met4020118

[27] Gordon, T., Perlstein, B., Houbara, O., Felner, I., Banin, E. and Margel, S. (2011) Synthesis and Characterization of Zinc/Iron Oxide Composite Nanoparticles and Their Antibacterial Properties. Colloids and Surfaces A: Physicochemical and Engineering Aspects, 374, 1-8. https://doi.org/10.1016/j.colsurfa.2010.10.015

[28] Cullity, B.D. (1978) Elements of X-Ray Diffraction. Addison-Wesley, Boston, MA, 359.

[29] Bushroa, A.R., Rahbari, R.G., Masjuki, H.H. and Muhamad, M.R. (2012) Approximation of Crystallite Size and Microstrain via XRD Line Broadening Analysis in TiSiN Thin Films. Vacuum, 86, 1107-1112. https://doi.org/10.1016/j.vacuum.2011.10.011

[30] Jaberolansar, E., Kameli, P., Ahmadvand, H. and Salamati, H. (2016) Synthesis and Characterization of PVP-Coated $\mathrm{Co}_{0.3} \mathrm{Zn}_{0.7} \mathrm{Fe}_{2} \mathrm{O}_{4}$ Ferrite Nanoparticles. Journal of Magnetism and Magnetic Materials, 404, 21-28. 